\title{
Arts zijn in Nederland. Hoe ziet de ideale arts eruit in de ogen van buitenlandse arts-studenten en wat denken zij over de Nederlandse gezondheidszorg?
}

\author{
A.L.M. Lagro-Janssen • M.E.T.C. van den Muijsenbergh
}

Samenvatting Doel: Vaststellen of er verschillen zijn tussen Nederlandse medisch studenten en buitenlandse artsstudenten in hun opvattingen over de ideale arts, en het verwerven van inzicht in de meningen van buitenlandse arts-studenten over een aantal karakteristieke kenmerken van de Nederlandse gezondheidszorg.

Opzet: Enquête en diepte-interviews.

Methode: In de periode januari-maart 2005 werden de opvattingen van buitenlandse artsstudenten van het UMC St. Radboud gemeten met behulp van een gevalideerde attitude vragenlijst. De meningen over kenmerken van de Nederlandse gezondheidszorg zijn geïnventariseerd door middel van interviews.

Resultaten: Van de 51 buitenlandse arts-studenten heeft $75 \%(n=38)$ de vragenlijst correct ingevuld en geretourneerd. Uit de antwoorden blijkt dat de attitude van de onderzochte buitenlandse arts-studenten minder care-gericht is dan de attitude van de zesdejaars Nederlandse studenten. Bovendien blijken de buitenlandse arts-studenten voldoende kennis en besef te hebben van een aantal karakteristieke kenmerken van de Nederlandse gezondheidszorg en van de hier vigerende opvattingen over de ideale attitude van de arts. Zij delen deze echter slechts zeer ten dele.

Conclusie: De onderzochte buitenlandse arts-studenten hebben een minder care-gerichte attitude dan de zesdejaars Nederlandse studenten. Zij staan kritisch ten aanzien van een aantal kenmerken van de Nederlandse gezondheidszorg. In het medisch onderwijs moet meer aandacht besteed worden aan deze aspecten en het volgen van de ontwikkeling van de attitude, zodat vastgesteld kan worden of het medisch onderwijs leidt tot een attitudevorming in de gewenste richting. (Lagro-Janssen ALM, Muijsenbergh METC van den. Arts zijn in Nederland. Hoe ziet de ideale arts eruit in de ogen van buitenlandse arts-studenten en wat denken zij over de Nederlandse gezondheidszorg? Tijdschrift voor Medisch Onderwijs 2007;26(1):11-18.)

\section{Inleiding}

De laatste jaren is de culturele diversiteit in Nederland en daarmee ook de culturele diversiteit van de medisch studenten toegenomen. Ook buitenlandse artsen die al een medische opleiding in een land buiten de Europese Unie hebben voltooid, dragen bij aan die culturele diversiteit. Deze buitenlandse artsen moeten aan een aantal voorwaarden voldoen voordat ze in de Nederlandse gezondheidszorg aan het werk mogen. Zij kunnen beginnen met hun opleiding nadat ze een nationale taaltoets voldoende hebben afgelegd. Aan de medische faculteit van de Radboud Universiteit bestaat hun opleiding uit het volgen van zes basisvakken in het vierde jaar (half jaar) en het doorlopen van de coschappen (twee jaar).

De toename van de culturele diversiteit onder medisch studenten biedt mogelijkheden om binnen de medische opleiding kennis uit te wisselen over culturen en religies en daarmee de studenten de kans te geven om ervaring op te doen met interculturele communicatie. 1 Echter, interculturele verschillen brengen ook obstakels met zich mee. In het contact tussen Nederlandse artsen en allochtone patiënten blijken regelmatig problemen op te treden. Deze problemen liggen met name op het vlak van communicatie, het verwachtingspatroon van de patiënt en verschillen in opvatting over gezondheid en ziekte.2-4 Het is te verwachten dat deze problemen ook optreden in een omgekeerde situatie, dus in het contact tussen een allochtone arts en een Nederlandse patiënt. 
Attitude is het complex van persoonskenmerken, normen, waarde, gevoelens, ideeën en meningen dat bepaalt hoe een persoon zich in een bepaalde situatie gedraagt. Attitudes zijn dus een reflectie van culturele waarden. Belgische medisch studenten bijvoorbeeld hebben een minder care-gerichte attitude dan hun Nederlandse collegae door de paternalistische arts-patiëntrelatie die in België als de norm wordt beschouwd.5

In Nederland wordt gestreefd naar een arts-patiëntrelatie die uitgaat van een patiënt- of care-gerichte attitude (humane geneeskunde) boven een arts- of cure-gerichte attitude (technologische geneeskunde). In een studie onder Nijmeegse studenten wordt geconcludeerd dat een meerderheid vindt dat de ideale arts een care-(patiënt-)gerichte attitude bezit. 6 Een beperkt gebruik van medicatie en een huisarts als poortwachter voor de tweede lijn zijn andere belangrijke waarden in ons gezondheidsstelsel.2 Ook het liberale abortus- en euthanasiebeleid is karakteristiek voor Nederland. Het is mogelijk dat buitenlandse artsen door hun andere cultuur en opleiding minder belang hechten aan deze kenmerken van de Nederlandse gezondheidszorg. Dit onderzoek stelt daarom de volgende vragen:

1. Verschillen Nijmeegse studenten en buitenlandse artsstudenten in hun attitude ten opzichte van de ideale arts?

2. Zijn er verschillen in hetgeen de buitenlandse artsstudenten beschrijven als de ideale arts in Nederland en die in het land van herkomst?

3. Hoe staan buitenlandse arts-studenten tegenover een aantal karakteristieke kenmerken van de Nederlandse gezondheidszorg?

Het doel van deze studie is om meer inzicht te krijgen in de achtergrond van buitenlandse arts-studenten en hun meningen ten aanzien van de arts-patiëntrelatie en opvattingen in de Nederlandse gezondheidszorg.

\section{Methode}

Aan alle 51 buitenlandse artsen die tussen januari en maart 2005 studeerden aan de Faculteit der Medische Wetenschappen van de Radboud Universiteit te Nijmegen, werd een enquête met begeleidende brief gestuurd. De enquête bestond uit vragen over de achtergrond van de respondenten en een Ideale Arts-vragenlijst.7 De Ideale Arts-vragenlijst bestaat uit achttien eigenschappen en hun tegenpool, bijvoorbeeld 'democratisch' versus 'hiërarchisch'. Per eigenschap kan op een 7-puntsschaal aangegeven worden of deze eigenschap belangrijk wordt geacht voor een ideale arts. Een hogere score wijst op een care-(patiënt-) gerichte attitude en een lagere score op een cure-(arts-)gerichte attitude. Tot slot is gevraagd aan de respondenten of zij mee wilden werken aan een interview. Bij allen die toestemden, is vervolgens een semigestructureerd interview afgenomen. Het eerste deel van het interview bestond uit een mondelinge toelichting op de Ideale Arts-vragenlijst. In het tweede deel werden enkele, volgens de literatuur typisch Nederlandse kenmerken van de gezondheidszorgverlening aan de orde gesteld, zoals het beperkt gebruik van medicatie en de beperkte verwijzing naar de tweede lijn.2 Tijdens het interview werd gevraagd om Nederland en het land van herkomst te vergelijken en er werd gevraagd naar de persoonlijke voorkeur van de arts-studenten voor de verschillende opvattingen.

De resultaten van de vragenlijsten zijn geanalyseerd en vergeleken met de data van de zesdejaars studenten uit eerder genoemd onderzoek.6 Alle berekeningen zijn uitgevoerd met behulp van SPSS. Verschillen in attitudescores zijn vergeleken door middel van een t-test. Significantie is bepaald bij $\mathrm{p}<0.05$. De interviews werden opgenomen op de band, woordelijk uitgetypt en na zorgvuldig lezen geanalyseerd door de twee onderzoekers.

\section{Resultaten}

De vragenlijst is door $76.5 \%(n=39)$ ingevuld. Vanwege onvolledigheid vervalt één enquête bij de verdere analyse $(75 \%)$. Van de respondenten was $63.2 \%(n=24)$ vrouw en $36.8 \%(n=14)$ man, met een gemiddelde leeftijd van 37.8 jaar ( $\mathrm{SD} \pm 5.2$ jaar). De respondenten waren afkomstig uit: Afghanistan (12), Irak (6), Iran (5), Rusland/ Sovjet-Unie (3), Roemenië (2) en overige landen. De respondenten waren vergelijkbaar met de totale groep wat betreft leeftijd (37.7 jaar; $\mathrm{SD} \pm 5.5$ jaar), geslacht $(62 \%$ versus $38 \%)$ en land van herkomst. Zeven van de 38 respondenten hadden een specialisatie afgerond in respectievelijk interne geneeskunde, epidemiologie en pathologie, kindergeneeskunde, oogheelkunde, sociale geneeskunde, psychiatrie en anesthesie. Gemiddeld hadden de artsen 4 jaar en 10 maanden werkervaring in het buitenland, met een range van 0-20 jaar.

De ideale arts

Gemiddeld scoorden de buitenlandse artsstudenten significant minder care-gericht (3.88; SD 0.31) op de Ideale Arts-vragenlijst dan de zesdejaars Nijmeegse studenten (4.11; SD 0.44). Dit verschil was vooral groot op zeven items (tabel 1). De ideale arts was in de ogen van de buitenlandse arts-studenten objectiverender, specialistischer, meer wetenschapper dan hulpverlener, analyserender, verstandelijker, eerder ingrijpend dan beschouwend 
Tabel 1 Verschillen Ideale Arts-vragenlijst tussen buitenlandse arts-studenten en zesdejaars Nederlandse studenten.

\begin{tabular}{|c|c|c|}
\hline Item & $\begin{array}{r}\text { Buitenlands } \\
\mathrm{n}=38 \\
\text { Gem (SD) }\end{array}$ & $\begin{array}{r}\text { Nederlands } \\
\mathrm{n}=116 \\
\text { Gem (SD) }\end{array}$ \\
\hline Gemiddelde alle 18 kenmerken & $3.88(0.31)$ & $4.11(0.44)^{*}$ \\
\hline Leidend - volgend & $3.55(1.45)$ & $3.28(0.97)$ \\
\hline Hiërarchisch - democratisch & $4.82(1.67)$ & $4.84(1.31)$ \\
\hline Afstandelijk - betrokken & $5.39(1.46)$ & $5.46(1.03)$ \\
\hline Objectiverend - invoelend & $3.68(1.32)$ & $4.29(1.10)^{*}$ \\
\hline Zakelijk - zorgzaam & $4.84(1.41)$ & $4.45(1.21)$ \\
\hline Terughoudend - mededeelzaam & $5.21(1.28)$ & $5.17(1.02)$ \\
\hline Somatisch - psychosociaal & $3.87(1.19)$ & $3.73(0.93)$ \\
\hline Technicus - biechtvader & $4.08(1.19)$ & $3.59(0.91)^{*}$ \\
\hline Specialist - generalist & $3.16(1.46)$ & $3.90(1.12)^{*}$ \\
\hline Wetenschapper - hulpverlener & $4.26(1.39)$ & $4.78(1.09)^{*}$ \\
\hline Solist - teamlid & $4.76(1.64)$ & $5.30(1.21)$ \\
\hline Analyserend - integrerend & $3.63(1.38)$ & $4.16(1.07)^{*}$ \\
\hline Gericht op ziekte - gericht op zieke & $4.26(2.02)$ & $4.72(1.17)$ \\
\hline Verstandelijk - emotioneel & $2.55(1.29)$ & $3.25(1.09)^{*}$ \\
\hline Logisch - intuïtief & $3.11(1.39)$ & $3.22(1.00)$ \\
\hline Nuchter - gevoelig & $3.74(1.47)$ & $3.72(1.15)$ \\
\hline Ingrijpend - beschouwend & $3.18(1.49)$ & $3.76(1.00)^{*}$ \\
\hline Zeker - twijfelend & $1.82(1.21)$ & $2.34(1.14)^{*}$ \\
\hline
\end{tabular}

* Significant verschil buitenlands-Nederlands $(\mathrm{p}<0.05)$.

en zekerder vergeleken met de opvattingen van de zesdejaars Nederlandse studenten. Op het item 'technicusbiechtvader' zagen zij de ideale arts meer als een biechtvader dan als een technicus, hetgeen in de schaal als meer care-gericht wordt geduid.

Elf onderzochte buitenlandse arts-studenten stemden toe in een interview. Bij allen van hen zijn interviews afgenomen, 6 vrouwelijke en 5 mannelijke arts-studenten. Hun gemiddelde leeftijd was 36.7 (SD 4.1 jaar). Ze waren afkomstig uit Irak, Roemenië, Iran (2), Peru, Afghanistan (2), Libanon, Turkije, Georgië en Mongolië. Het betrof 3 zesdejaars, 4 vijfdejaars en 4 vierdejaars studenten.

Op de vraag om de ideale arts te beschrijven, werden spontaan de volgende kenmerken het meeste genoemd: betrokkenheid $(n=8)$, goede communicatievaardigheden $(n=7)$, goede deskundigheid en kennis $(n=5)$, persoonlijke benadering van de patiënt $(n=4)$, goede luistervaardigheden $(n=3)$ en specialistische kennis $(\mathrm{n}=3)$.

Verschillen tussen Nederland en het land van herkomst

Gevraagd naar verschillen tussen de Nederlandse gezondheidszorg en die in het land van herkomst, werd regelmatig $(n=8)$ het verschil in de positie van de arts genoemd. In het land van herkomst heeft de arts vaak een hoge status $(\mathrm{n}=7)$ en is er meer afstand tussen arts en patiënt $(\mathrm{n}=5)$.

"Kijk, in Iran is de positie van de arts veel hoger, echt hoger, en de arts speelt bijna de rol van een god (...) hier heeft de arts heel veel medeleven met de patiënt en dat is niet zo in Iran." (man, 31 jaar)

"In jullie land is een arts een soort dienaar, in ons land is het een god." (man, 35 jaar)

Artsen in het land van herkomst zijn vaak alleen op de lichamelijke klachten gericht $(n=6)$. De Nederlandse artsen zijn volgens de buitenlandse arts-studenten sociaal, hebben veel empathie $(n=6)$ en hebben veel kennis van sociale zaken nodig $(n=4)$. Twee respondenten noemden het directe en open karakter van de slecht nieuws-gesprekken als iets dat hen tegen de borst stuitte. "In Georgië is dat (slecht nieuws) nooit direct tegen de patiënt, maar tegen de familie of kennissen. Het direct zeggen tegen de patiënt: "sorry maar u hebt kanker in uw hersenen. Ja, u gaat straks overlijden", dat doe ik niet.... je moet tot het laatste moment hoop geven aan de patiënt." (vrouw, 42 jaar)

Ook het raadplegen van boeken in het bijzijn van patiënten had een aantal respondenten geschokt $(\mathrm{n}=4)$.

"Wat ik ook shockerend vond hier, bij de specialist of bij de huisarts, is dat zij een boek openen met de patiënt erbij. Bij ons mag dat niet (...) anders hebben ze geen vertrouwen in je, zij denken dan: "hij weet niks, hij opent zomaar een boek." (man, 33 jaar) 
Zes arts-studenten gaven de voorkeur aan de manier van werken in Nederland, twee omdat ze nu eenmaal in Nederland woonden. Drie respondenten zagen vóór- en nadelen in de werkwijze van artsen in Nederland en in het land van herkomst. Eén arts-student vondt dat er te weinig afstand was tussen arts en patiënt in Nederland en dat de patiënten te veel vrijheid hadden. Eén artsstudent noemde de gewoonte in Nederland om empathie te tonen theaterspel.

“....teveel vrijheid en teveel rechten hebben de patiënten en dan kom je in de problemen." (vrouw, 38 jaar)

“... jullie leren op de faculteit hoe met de patiënten om te gaan, met empathie. Met theaterspelen (...) hier leert een arts goed theater spelen." (man, 35 jaar)

Als grootste verschillen tussen Nederland en het land van herkomst in de verwachtingen van de patiënt werden genoemd dat patiënten in het land van herkomst veel meer medicatie willen krijgen $(\mathrm{n}=8)$, veel minder kennis van ziekten bezitten $(n=4)$ en het vragen naar psychosociale factoren absoluut niet gewenst vinden $(n=4)$.

Meningen over kenmerken van de Nederlandse gezondheidszorg

Tien respondenten beoordeelden het beperkt voorschrijven van medicatie in het algemeen als een goede zaak, echter vijf van hen vonden het soms te star en twee achtten een goede uitleg hierover per se noodzakelijk.

“... soms lijkt het wel alsof de artsen paracetamol voor alles geven. Ik vind het beperkt voorschrijven wel een goede zaak, maar soms is het een beetje te streng." (vrouw, 32 jaar)

Hoewel de arts-studenten wel instemden met het strikte verwijsbeleid naar de tweede lijn, vonden vier van hen dat verwijzing sneller kon. Drie respondenten oordeelden dat er vaak te weinig uitleg gegeven werd en één respondent vond dat het mogelijk moest zijn om direct naar een specialist te gaan.

Drie arts-studenten hadden nog nooit van euthanasie gehoord en wisten niet wat het was. Het was nog nooit in hun onderwijs aan de orde gekomen. Na uitleg wezen zeven respondenten de mogelijkheid van euthanasie niet zonder meer af, hoewel twee van hen sterk aarzelden wegens angst voor misbruik. Van deze zeven waren er slechts drie bereid tot het zelf uitvoeren van euthanasie. Vier respondenten waren fel tegen.

"Er is altijd een genezing voor een ziekte, maar misschien kunnen wij die nog niet vinden, vanwege dit kunnen wij geen mensen doodmaken. Misschien komt de genezing en dan is iemand al dood." (man, 35 jaar)

Vrijwel iedereen $(n=9)$ accepteerde dat de mogelijkheid tot abortus in Nederland bestaat. Bij de term 'abortus' dachten alle arts-studenten overigens niet spontaan aan abortus op verzoek, zoals bedoeld bij deze vraag, maar aan abortus op medische indicatie. Drie respondenten vonden ook dat abortus alleen op medische indicatie, zoals erfelijke afwijkingen van het kind of gevaar voor de gezondheid van de moeder, zou mogen gebeuren. Een van de respondenten die abortus niet principieel verwierp, zou het niet zelf willen uitvoeren. Twee anderen vonden dat armoede en kindersterfte een argument is voor abortus, maar niet een zwangerschap die ongewenst is of ongelegen komt.

"In arme landen mag het wel, want dat kind sterft soms van de armoede. ... In de rijke landen zoals Nederland krijgt het kind geen problemen" (man, 35 jaar).

Twee respondenten stonden negatief tegenover elke vorm van abortus provocatus.

\section{Beschouwing}

De belangrijkste bevinding van dit onderzoek is dat de attitude van de onderzochte buitenlandse arts-studenten minder patiëntgericht is dan de attitude van de zesdejaars Nederlandse studenten. Dit blijkt uit de resultaten van de vragenlijsten en wordt extra ondersteund door de resultaten van de interviews. Hun meningen over de ideale arts lijken sterk te worden beïnvloed door het land van herkomst. Daar, zo blijkt immers uit de interviews, wijzen de invloedrijke positie van de arts, de hiërarchische arts-patiëntrelatie en de verwachtingen van de patiënten op een meer arts- dan patiëntgerichte opstelling. Dat kan een verklaring zijn voor de problemen die er regelmatig blijken op te treden in het contact tussen een buitenlandse arts en Nederlandse patiënten. 8

De arts-studenten schetsen het beeld van een ideale arts zoals die in Nederland gewenst is: betrokken, met goede communicatievaardigheden en een goede opleiding. Alle respondenten zijn zich bewust van de verschillen tussen het land van herkomst en Nederland en de implicaties van deze verschillen. Ze geven aan dat het voor de arts-patiëntrelatie belangrijk is om als arts aangepast te zijn aan de in Nederland geldende norm. Een meerderheid geeft dan ook de voorkeur aan de Nederlandse manier van werken. Tegelijkertijd uiten ze ook duidelijk andere, tegenovergestelde, meningen. Zo keuren ze het directe slecht nieuws-gesprek af, evenals het naslaan van leerboeken in het bijzijn van patiënten. Ook het beperkt voorschrijven van medicatie oogst kritiek, evenals de ervaren traagheid van het verwijsbeleid. Ook bij abortus wordt in eerste instantie aan een abortus provocatus op medische indicatie gedacht en is er een terughoudend beleid.

Op het punt van het Nederlandse euthanasiebeleid bestaat de grootste discrepantie tussen de in Nederland 
vigerende opvattingen en die van de buitenlandse artsstudenten. Gezien de discussie die er in vele landen gevoerd wordt over het Nederlandse euthanasiebeleid en de religieuze achtergronden van de arts-studenten is dit niet verwonderlijk. Dat drie respondenten niet weten wat euthanasie inhoudt geeft een hiaat in het onderwijs aan. Onze studie kent een aantal beperkingen. Als vergelijkingsmateriaal stond ons een recente studie naar de Ideale Arts Schaal van de zesdejaars studenten in Nijmegen ter beschikking. Onze respondenten zijn echter deels vierde- en vijfdejaars. In de studie van Batenburg bleek geen verschil tussen vierde- en zesdejaars studenten t.a.v. de ideale arts.6 Bovendien kan niet uitgesloten worden dat de geïnterviewden, ondanks de ruime variatie in achtergrondkenmerken, toch niet gevarieerd genoeg waren zoals gewenst is in kwalitatief onderzoek. Wellicht missen we daardoor nog interessante meningen en opvattingen van buitenlandse arts-studenten. Desalniettemin denken we dat deze studie meer inzicht heeft gegeven in welke culturele waarden uit het land van herkomst van belang kunnen zijn bij de attitude van buitenlandse artsstudenten.

\section{Conclusie}

Uit dit onderzoek blijkt dat de onderzochte buitenlandse arts-studenten een minder care-gerichte attitude hebben dan de zesdejaars Nederlandse studenten. De interviews bevestigen dit in hoge mate: de

onderzochte buitenlandse arts-studenten

laten kritische geluiden horen ten aanzien van openheid en zijn minder terughoudend

in het voorschrijven van medicatie

en het verwijzen naar de tweede lijn. De

buitenlandse respondenten hebben voldoende

kennis en besef van een aantal karakteristieke

kenmerken van de arts-patiëntrelatie,

maar ze verkiezen toch een

aantal meer hiërarchische waarden. Daarnaast

keurt een groot aantal respondenten

de liberale Nederlandse opvattingen ten

aanzien van euthanasie en abortus provocatus

af. In het onderwijs is expliciete

aandacht gewenst voor culturele verschillen

in de gezondheidszorg en voor kenmerken

van de gezondheidszorg die in

Nederland hoog gewaardeerd worden dan

wel afwijkend zijn van de meeste andere

landen, zoals het euthanasiebeleid. Het

onderwijs zou zich niet moeten beperken

tot louter overdracht van informatie in

dezen, maar ook moeten evalueren in praktijksituaties hoe de buitenlandse artsstudenten

deze aspecten integreren in

hun eigen professioneel handelen.

Daarom is het belangrijk om competenties

nog beter te expliciteren en om de

ontwikkeling in competenties te volgen,

zodat vastgesteld kan worden of het medisch

onderwijs een attitudevorming in de

gewenste richting effectueert.

\section{Dankwoord}

Dank aan Suzanne Bouwman, medisch

student, voor het verzamelen van de data.

Belangenconflict: geen gemeld.

Financiële ondersteuning: geen gemeld.

\section{Summary}

Objective: To investigate any differences between Dutch medical students and foreign doctor-students in their views of the ideal doctor and to investigate what foreign doctor-students think of certain characteristics of the Dutch health care system.

Design: Validated questionnaires and interviews.

Method: During the period of January-March 2005, the opinions of foreign doctor-students at the UMC St Radboud were sought by means of a validated attitude questionnaire. Additionally, opinions about some characteristics of the Dutch health care system were investigated by means of in-depth interviews.

Results: Thirty-eight $(75 \%)$ of the total of 51 foreign doctorstudents returned the completed questionnaire. Foreign doctorstudents appear to be less care orientated than sixth year Dutch undergraduate medical students. The foreign doctor-students appear to have sufficient knowledge and understanding of important characteristics of the Dutch health care system and of general opinions about the ideal attitude of doctors. However, they only share a small part of these views.

Conclusion: Our study shows that foreign doctor-students have a less care-orientated attitude than Dutch sixth year undergraduate medical students. The foreign doctor-students have a critical attitude toward certain characteristics of the Dutch health care system. The medical curriculum should pay more attention to this and to the development of attitude so that it can be determined whether medical education succeeds in fostering an appropriate attitude in students. (Lagro-Janssen ALM, Van den Muijsenbergh METC. Being a doctor in the Netherlands. What is the ideal doctor in the eyes of foreign doctor-students and what are their opinions of Dutch health care? Dutch Journal of Medical Education 2007;26 (1):11-18.)

\section{Literatuur}

Selleger VJ, Bonke B, Leeman YAM. Etnische en religieuze diversiteit van eerstejaarsstudenten geneeskunde aan de Erasmus Universiteit Rotterdam. Ned Tijdschr Geneeskd 2003;147 (17):806-9.

Lamberts SWJ. Interculturalisatie van het medisch onderwijs in Nederland. Ned Tijdschr Geneeskd 2003;147(17):789-92.

Eisenbruch M. Medical education for a multicultural society. Med J Aust 1989;151:574-80.

Wieringen JCM van, Harmsen JAM, Bruijnzeels MA. Intercultural communication in general practice. Eur $\mathrm{J}$ Public Health 2002;12:63-8. 
De Valck C, Bensing J. Cure oriented versus care oriented attitudes in medicine. Patiënt Educ Couns 2006;45:119-26.

Verdonk P, Harting EJ, Lagro-Janssen ALM. Does equal education generate equal attitudes? Gender differences in medical students' attitudes toward the ideal physician. Teach Learn Med 2007;19(1):9-13.
Batenburg V. Medical students' attitudes: attitude development in a medical school [dissertatie]. Utrecht: Elinkwijk; 1997.

Out JJ, Brienen JA, Schneider AJ. De cursus 'Attitudevorming en gespreksvoering voor buitenlandse artsen'. Tijdschrift voor Medisch Onderwijs 2001;20(2):76-82. 